\title{
Functional Traits and Reproductive Allocation Strategy of Conyza canadensis as they Vary by Invasion Degree Along a Latitude Gradient
}

\author{
Congyan Wang ${ }^{1,2 *}$, Jiawei Zhou ${ }^{1}$, Jun Liu ${ }^{1}$, Hongguang Xiao ${ }^{1}$, Lei Wang ${ }^{1}$ \\ 'Institute of Environment and Ecology, Academy of Environmental Health and Ecological Security \\ \& School of the Environment and Safety Engineering, \\ Jiangsu University, Zhenjiang 212013, P. R. China \\ ${ }^{2}$ State Key Laboratory of Soil and Sustainable Agriculture, Institute of Soil Science, \\ Chinese Academy of Sciences, Nanjing, 210008, P. R. China
}

Received: 9 September 2016

Accepted: 20 October 2016

\begin{abstract}
This study aims to determine the functional traits and reproductive allocation (RA) strategy of the invasive plant Conyza canadensis across different invasion degrees along a latitude gradient in China. Invasion degree did not affect the functional traits and RA strategy of $C$. canadensis significantly. The high proportion of reproductive biomass (allocating approximately $20 \%$ of total biomass into reproductive behaviors) of C. canadensis across different invasion degrees can achieve a fitness advantage in broadening its habitat niches and can eventually attain a successful invasion. The higher proportion of reproductive biomass of C. canadensis in warm temperate and subtropical monsoon climatic zones may play an important role in its successful invasion in the two climatic zones in China. One possible reason for this is that eastern China and northern China, in which $C$. canadensis vigorously occurs, have the same or similar climate as their natural habitat in the original distribution region. The proportion of reproductive biomass of C. canadensis positively correlated with its total biomass, aboveground biomass, belowground biomass, and vegetative biomass, as well as with its height and leaf size. Meanwhile, temperature rather than annual sunshine hours or annual precipitation was determined to be the most important environmental factor that triggers pronounced effects on the RA strategy of C. canadensis.
\end{abstract}

Keywords: functional traits, reproductive allocation strategy, invasion degree, latitude gradient, Conyza canadensis

*e-mail: liuyuexue623@163.com 


\section{Introduction}

At present, invasive plants have triggered serious threats to the structure and function of invaded ecosystems. Thus, ecologists have recently exerted efforts to elucidate the successful invasion mechanism of those invaders [12]. Some invasive plants have successfully occupied certain environments because of their highly efficient reproductive allocation strategy (RA, i.e., the proportion of biomass allocated to reproductive structures) [3]. Functional traits determine how plants reproduce and gain resources [4]. These traits affect the success of a species in competing with other species for living resources (e.g., nutrients) [5]. The reproduction behaviors of plants are closely associated with their acquired living resources [68]. Hence, learning the RA strategy of invasive plants is important for understanding the mechanism underlying successful plant invasion.

Invasive plants can establish populations in the colonized ecosystems after they are transported far from their original distribution region [1,9]. Thus, invasive plants can display different abundances in colonized ecosystems $[1,10]$ and their invasion may cross several climatic zones. For example, the notorious invasive plant Conyza canadensis has spread to most parts of China [10]. Thus, understanding the functional traits and RA strategy of $C$. canadensis across different invasion degrees along a latitude gradient is important for understanding the successful mechanism underlying plant invasion.

Cross-site comparisons were performed in this study to determine the functional traits and RA strategy of C. canadensis across different invasion degrees along a latitude gradient. C. canadensis is a herbaceous annual invasive weed of the Compositae family, which is native to North America [11]. At present, the species has become naturalized in China and is one of the most detrimental and widespread invasive species in most regions of China $[11,12]$. This species thrives in many habitats, especially in areas subject to human disturbance [13]. The results of this study can provide a platform to better understand the mechanism of successful invasion of $C$. canadensis and then lay an important theoretical foundation and practical significance for effective invasion prevention and control. This study tests the following two hypotheses. First, the reproductive biomass and RA of $C$. canadensis decrease with elevating invasion degree because the RA of the plant population decreases under competitive conditions [7,
14]. Second, $\mathrm{C}_{\mathrm{RA}}$ (the coefficient of RA) of C. canadensis positively correlates with its total biomass because plants invest a huge amount of biomass into their reproductive behaviors when they gain and use several resources $[6$, $15]$.

\section{Materials and Methods}

\section{Experimental Design}

Samples were obtained from the following four sampling sites along a latitude gradient in China: Shenyang $\left(41.82^{\circ} \mathrm{N}, 123.46^{\circ} \mathrm{E}\right.$, featuring a cold temperate climate), Jinan $\left(36.68^{\circ} \mathrm{N}, 116.90^{\circ} \mathrm{E}\right.$, featuring a warm temperate climate), Zhenjiang $\left(32.20^{\circ} \mathrm{N}, 119.51^{\circ} \mathrm{E}\right.$, featuring a subtropical monsoon climate), and Xiamen $\left(24.62^{\circ} \mathrm{N}\right.$, $118.07^{\circ} \mathrm{E}$, featuring a subtropical marine climate). The climate characteristics of these sampling sites are shown in Table 1.

From mid-August 2014 to mid-September 2014, C. canadensis samples were collected during their reproductive period (the growth stage of $C$. canadensis is mainly in the eighth stage, i.e., "Ripening of fruits and seeds" according to the BBCH-scale [16]) from the aforementioned sampling sites. The invasion degrees were divided into low $(<35 \%)$, moderate $(35 \%$ to $75 \%)$, and high $(>75 \%)$ on the basis of $C$. canadensis coverage in the invaded ecosystems. Three plant sample replicates of this species from the same quadrat $(1 \times 1 \mathrm{~m})$ per the same invasion degree in the same sampling site were collected randomly ( 3 plants $\times 3$ invasion degrees $\times 3$ replicates $\times 4$ sampling sites $=108$ individual plants). Five mature and flawless leaves of one plant sample were randomly selected to determine its functional traits.

\section{Determining Plant Characteristics and Diversity}

Plant height was determined between the base of the stem and the apical shoot by ruler measurement $[2,10]$.

Leaf shape index was calculated as the ratio of leaf length to the corresponding leaf width [17-19]. Leaf length is the maximum value along the large strengthened vein along the midline of a leaf, and leaf width is the maximum value perpendicular to the large strengthened vein along the midline of a leaf [17]. The leaf length and width of

Table 1. Differences in the climate characteristics of the sampling sites. Abbreviations: ASH, annual sunshine hours (h); MAP, mean annual precipitation $(\mathrm{mm})$; MAT, mean annual temperature $\left({ }^{\circ} \mathrm{C}\right)$; MiT, minimum temperature $\left({ }^{\circ} \mathrm{C}\right)$; MaT, maximum temperature $\left({ }^{\circ} \mathrm{C}\right)$; AAT, annual accumulated temperature $\left({ }^{\circ} \mathrm{C}\right)$.

\begin{tabular}{|c|c|c|c|c|c|c|}
\hline Site & ASH & MAP & MAT & MiT & MaT & AAT \\
\hline Shenyang & $2,372.00$ & 721.90 & 8.00 & -33.00 & 38.00 & $3,281.00$ \\
\hline Jinan & $2,481.10$ & 614.00 & 13.80 & -19.00 & 42.50 & $4,575.30$ \\
\hline Zhenjiang & $2,000.90$ & $1,088.00$ & 15.60 & -10.10 & 40.20 & $5,750.00$ \\
\hline Xiamen & $1,953.00$ & $1,143.00$ & 21.00 & 2.00 & 39.00 & $7,327.50$ \\
\hline
\end{tabular}


the plants were measured with a ruler with an accuracy of $0.1 \mathrm{~cm}$ [18-20].

The plant biomass was measured using an electronic balance. The belowground-aboveground biomass ratios were computed by dividing the belowground biomass by the corresponding aboveground biomass [10].

$\mathrm{C}_{\mathrm{RA}}$ was calculated using the ratio of reproductive biomass to total biomass $[10,21]$.

The Shannon-Wiener diversity $\left(H^{\prime}\right)$, Simpson dominance $(D)$, and Pielou evenness $\left(E_{H}\right)$ indices were used to estimate the community structure of the sites $(1 \times 1 \mathrm{~m})$ where $C$. canadensis is growing. $H^{\prime}$ was calculated as $H^{\prime}=-\Sigma P_{\mathrm{i}} \ln P_{\mathrm{i}}$ [22], where $P_{\mathrm{i}}$ is the relative abundance of one species. $P_{\mathrm{i}}$ was calculated as $P_{\mathrm{i}}=n_{\mathrm{i}} / N$, where $n_{\mathrm{i}}$ is the number of individuals of one species and $N$ is the sum of the number of all plants in the surveyed area. $D$ was calculated as $D=\Sigma\left(n_{\mathrm{i}} / N\right)^{2}$ [23]. $E_{H}$ was calculated as $E_{H}=H^{\prime} / \ln S$ [24], where $S$ is the number of all species in the surveyed area.

\section{Statistical Analyses}

Differences among various dependent variables were assessed using analysis of variance between groups followed by a multiple comparisons correction using the Student-Newman-Keuls test. Statistically significant difference was considered at $P$ values lower than 0.05 . Correlation patterns among various dependent variables were determined through correlation analysis (using Pearson product-moment correlation coefficient) and principal component analysis (PCA) using SPSS (version 17.0).

\section{Results}

Differences were observed among the functional traits and RA strategy of C. canadensis across different invasion degrees along a latitude gradient (Tables 2 and 3). No significant difference was discovered in the functional traits and RA strategy of $C$. canadensis across different invasion degrees $(P>0.05$; Table 2$)$. C. canadensis with high abundance significantly decreased Shannon-Wiener diversity $\left(H^{\prime}\right)$ and Pielou evenness $\left(E_{H}\right)$ of the community structure, but significantly increased Simpson dominance $(D)$ of the community structure $(P<0.05$; Table 2$)$.

The height, leaf length, leaf width, total, aboveground, belowground, vegetative, and reproductive biomass as well as belowground-aboveground biomass ratio of $C$. canadensis increased with decreasing latitude gradient in Shenyang, Jianan, and Zhenjiang $(P<0.05$; Table 3). Reproductive branch number and $\mathrm{C}_{\mathrm{RA}}$ of $C$. canadensis was in the order of Shenyang $<$ Xiamen $<$ Zhenjiang $<$ Jinan $(P<0.05$; Table 3$)$. No significant difference was discovered in leaf shape index of $C$. canadensis along a latitude gradient $(P>0.05$; Table 3$)$. Shannon-Wiener diversity $\left(H^{\prime}\right)$ of the community structure in Xiamen was significantly lower than that in Shenyang, Jinan, and Zhenjiang, but Simpson dominance $(D)$ of the community

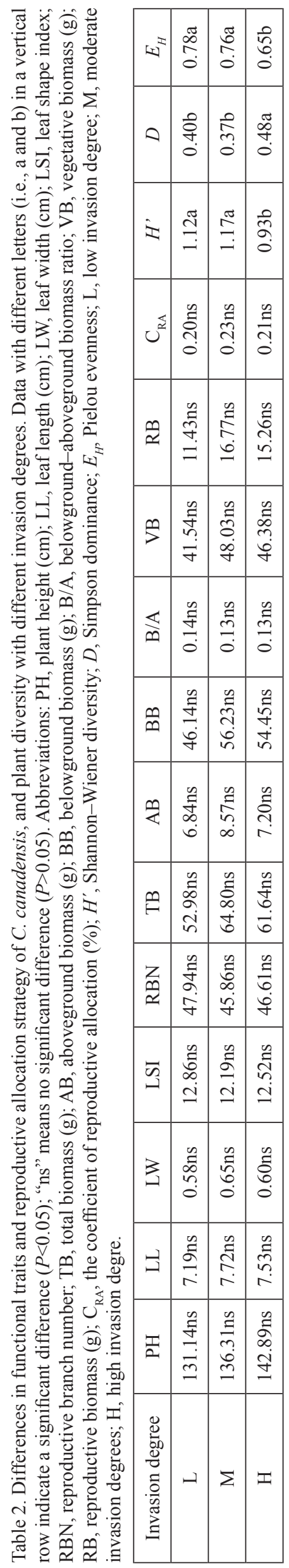




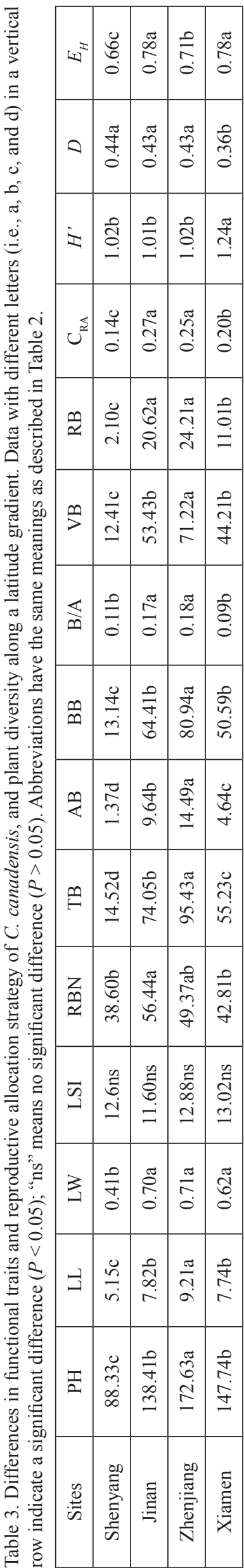

structure in Xiamen was significantly higher than that in Shenyang, Jinan, and Zhenjiang $(P<0.05$; Table 3$)$. Pielou evenness $\left(E_{H}\right)$ of the community structure decreased in the following order: Jinan/Xiamen, Zhenjiang, and Shenyang $(P<0.05$; Table 3$)$.

Many significant correlations were revealed among the functional traits of C. canadensis, the plant diversity of the community structure of the sites, and the climate characteristics of the sampling sites along a latitude gradient (Table 4). In particular, the annual sunshine hours was positively correlated with Simpson dominance $(D)$ of the community structure $(P<0.01)$, but negatively correlated with the height, leaf length, leaf shape index, total biomass, aboveground biomass, belowground biomass, and vegetative biomass of $C$. canadensis, as well as with Shannon-Wiener diversity $\left(H^{\prime}\right)$ of the community structure $(P<0.05)$. The relationship between annual precipitation and other indices were all opposite $(P<0.01)$. The mean annual air temperature, minimum temperature, and annual accumulated temperature were positively correlated with the height, leaf length, leaf width, total biomass, aboveground biomass, belowground biomass, vegetative biomass, and reproductive biomass, as well as with $\mathrm{C}_{\mathrm{RA}}$ of $C$. canadensis $(P<0.05)$. In addition, these temperature parameters were positively correlated with Shannon-Wiener diversity $\left(H^{\prime}\right)$ and Pielou evenness $\left(E_{H}\right)(P<0.01)$, but negatively correlated with Simpson dominance $(D)$ of the community structure $(P<0.001)$. The maximum temperature was positively correlated with the height, leaf length, leaf width, reproductive branch number, total biomass, aboveground biomass, belowground biomass, vegetative biomass, and reproductive biomass, belowground-aboveground biomass ratio, and $\mathrm{C}_{\mathrm{RA}}$ of $C$. canadensis, as well as with Pielou evenness $\left(E_{H}\right)$ of the community structure $(P<0.01)$. The height of $C$. canadensis was positively correlated with its leaf length, leaf width, reproductive branch number, total biomass, aboveground biomass, belowground biomass, vegetative biomass, and reproductive biomass, as well as with the $\mathrm{C}_{\mathrm{RA}}(P<0.01)$. The leaf length of $C$. canadensis was positively correlated with its leaf width, total biomass, aboveground biomass, belowground biomass, vegetative biomass, and reproductive biomass, as well as with belowground-aboveground biomass ratio and $\mathrm{C}_{\mathrm{RA}}(P<0.05)$. The leaf width of $C$. canadensis was positively correlated with its total biomass, aboveground biomass, belowground biomass, vegetative biomass, and reproductive biomass as well as with $\mathrm{C}_{\mathrm{RA}}(P<0.001)$. By contrast, leaf shape index of $C$. canadensis was negatively correlated with its total biomass, belowground biomass, vegetative biomass, and reproductive biomass $(P<0.05)$. The reproductive branch number of $C$. canadensis was positively correlated with its total biomass, aboveground biomass, belowground biomass, vegetative biomass, and reproductive biomass, as well as with Pielou evenness $\left(E_{H}\right)$ of the community structure $(P<0.01)$. The total biomass, aboveground biomass, belowground biomass, and vegetative biomass of $C$. canadensis was positively correlated with its reproductive biomass and $\mathrm{C}_{\mathrm{RA}}(P<0.01)$. 


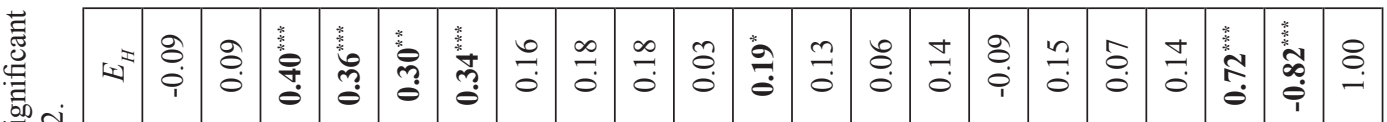

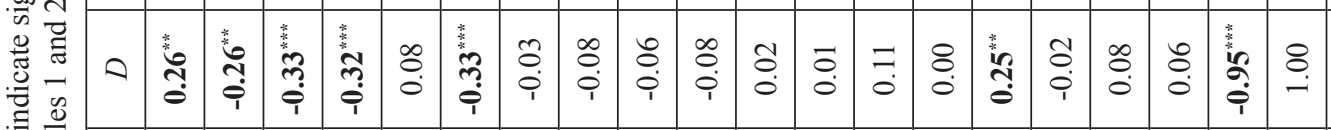

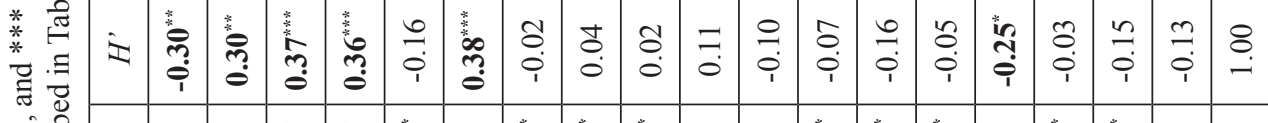

* * *

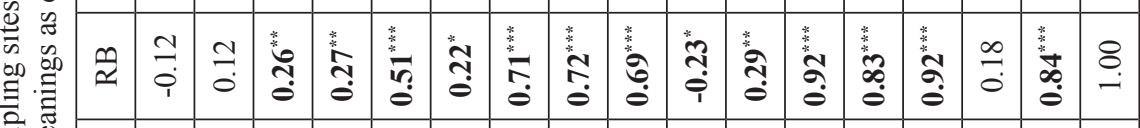

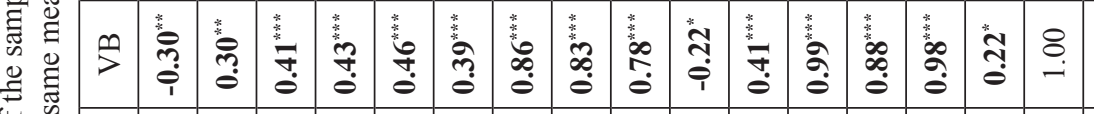

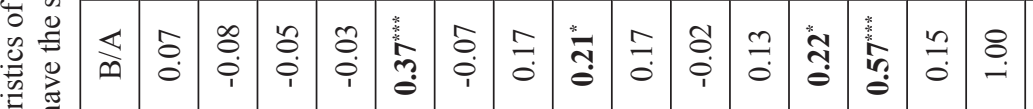

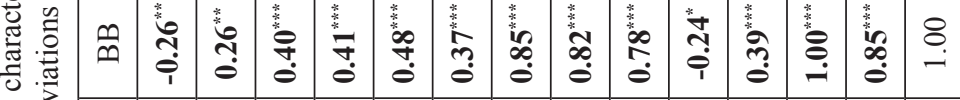

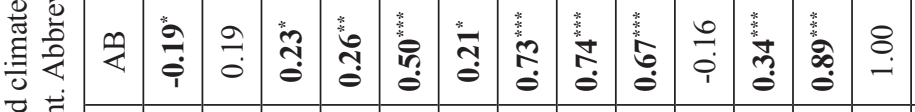

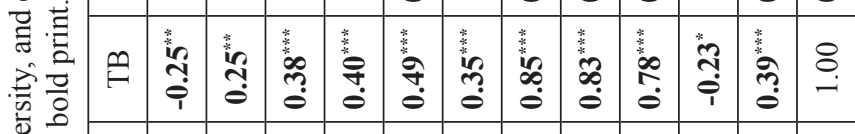

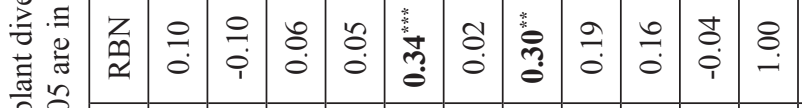

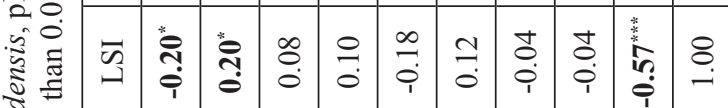

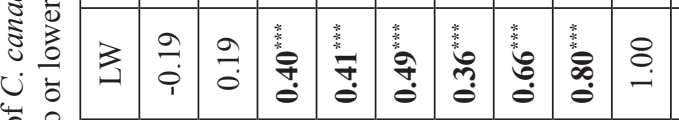

요

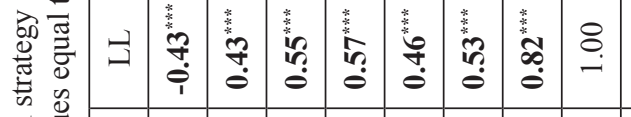

흘

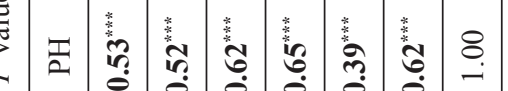

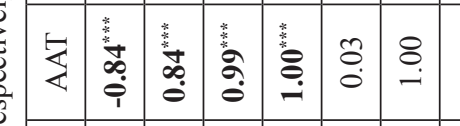

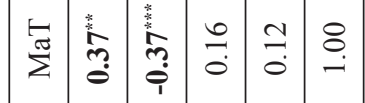

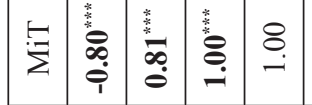

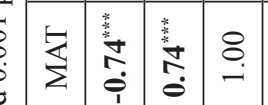

$$
\text { (1) }
$$

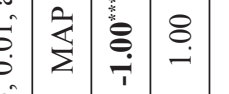

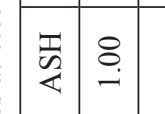

+ำ 


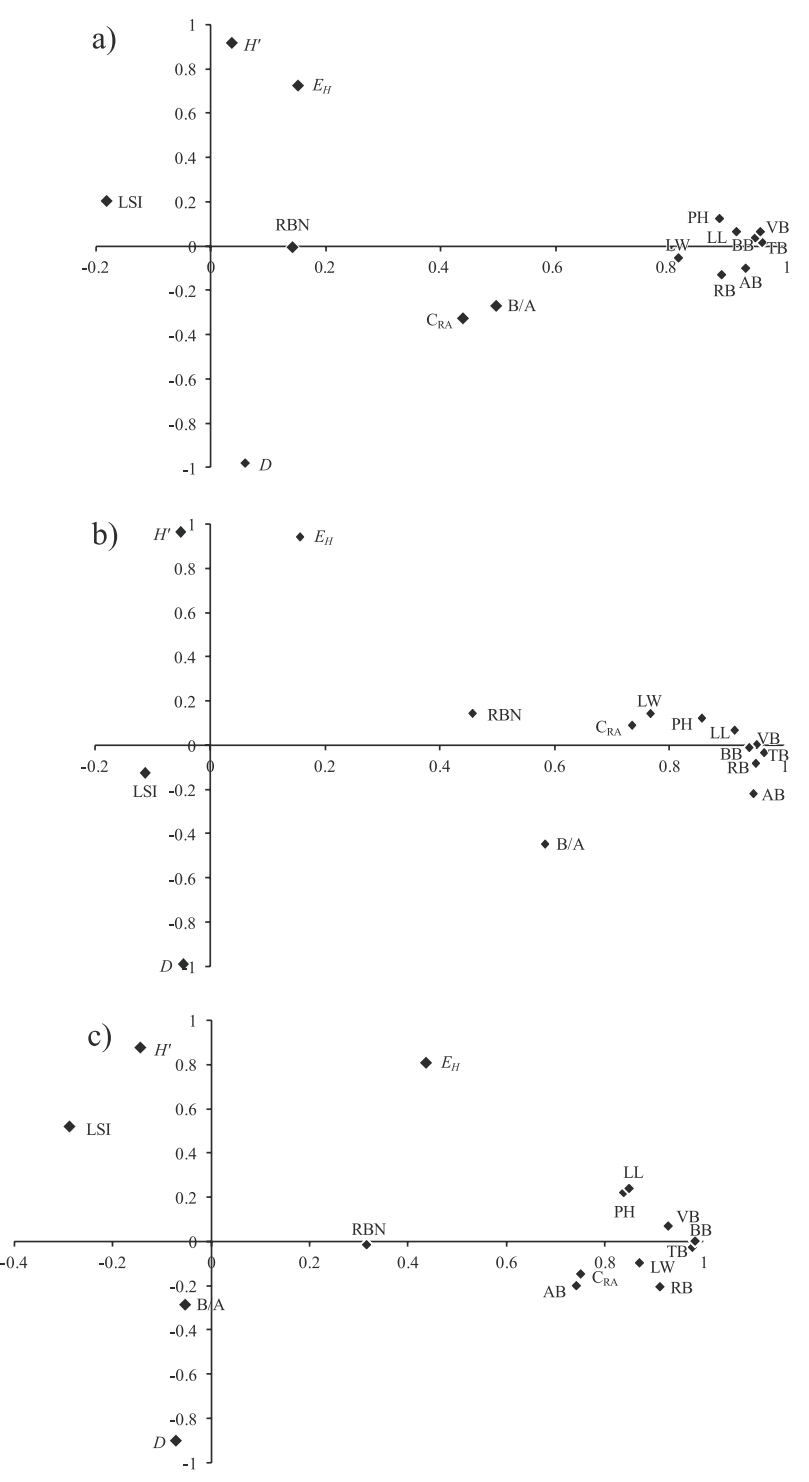

Fig. 1. PCA of the correlation patterns of the functional traits and reproductive allocation strategy of $C$. canadensis and plant diversity with different invasion degrees. The $X$ axis account for $47.74 \%, 51.89 \%$, and $48.73 \%$ of the total variation in low a), medium b), and high c) invasion degrees of $C$. canadensis, respectively, and the $Y$ axis account for $17.38 \%, 20.97 \%$, and $18.80 \%$ of the total variation in low a), medium b), and high c) invasion degree of $C$. canadensis, respectively. Abbreviations have the same meanings as described in Table 2 .

The belowground-aboveground biomass ratio of $C$. canadensis was positively correlated with its vegetative biomass and with Simpson dominance $(D)$ of the community structure $(P<0.05)$, but negatively correlated with Shannon-Wiener diversity $\left(H^{\prime}\right)$ of the community structure $(P<0.05)$.

Correlation patterns between the functional traits and reproductive allocation strategy of $C$. canadensis and plant diversity in the distribution area of $C$. canadensis across different invasion degrees along a latitude gradient were separately examined by PCA (Figs 1 and 2). In particular, correlations between $\mathrm{C}_{\mathrm{RA}}$ and belowground-aboveground biomass ratio of $C$. canadensis were strengthened under a)
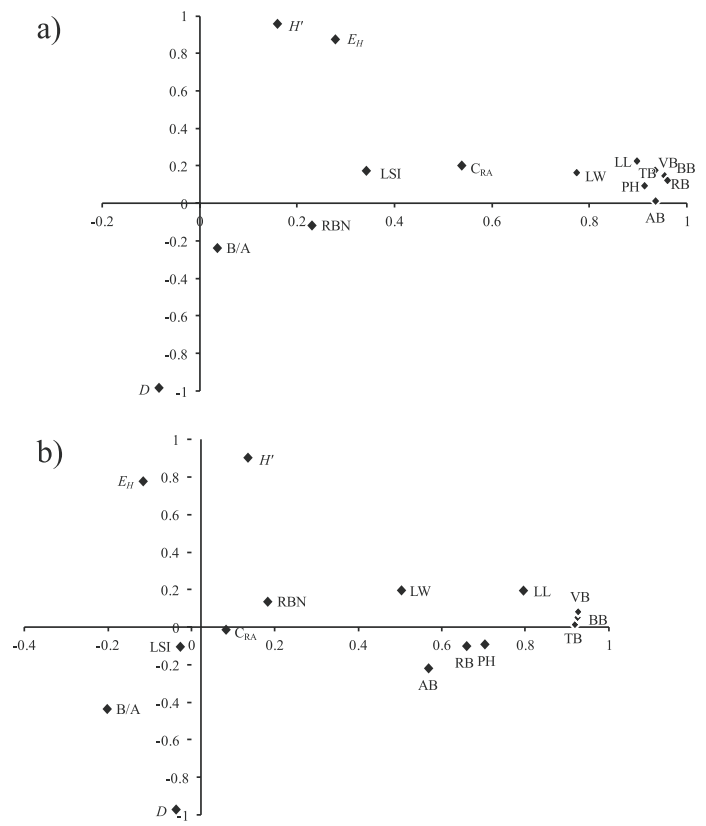

c)
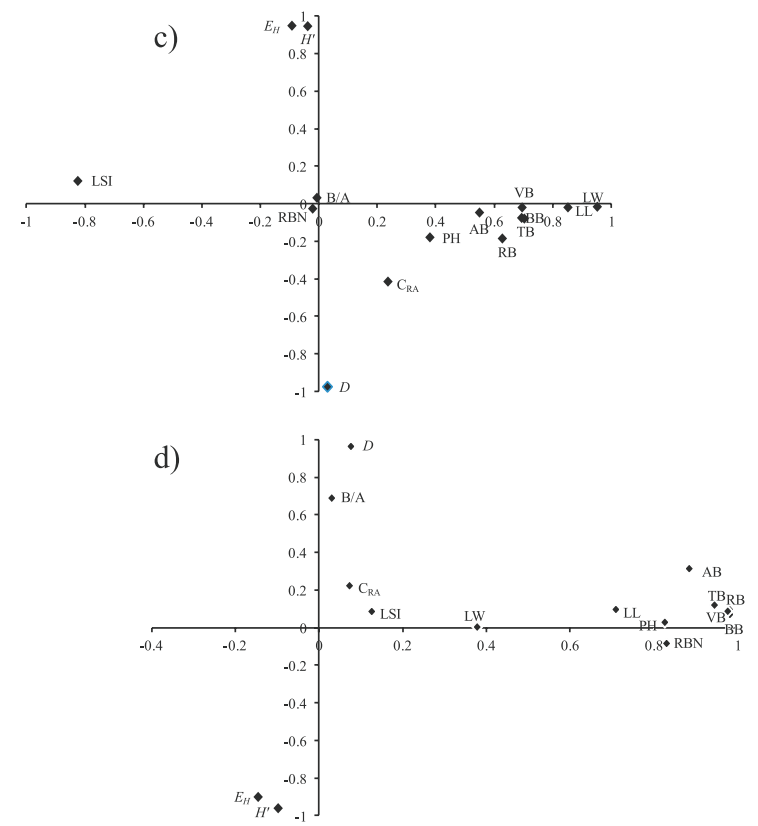

Fig. 2. PCA of the correlation patterns of the functional traits and reproductive allocation strategy of $C$. canadensis and plant diversity along a latitude gradient. The $X$ axis account for $48.60 \%, 31.96 \%, 31.07 \%$, and $44.10 \%$ of the total variation in Shenyang a), Jinan b), Zhenjiang c), and Xiamen d), respectively, and the $Y$ axis account for $19.77 \%, 18.27 \%, 20.14 \%$, and $22.36 \%$ of the total variation in Shenyang a), Jinan b), Zhenjiang c), and Xiamen d), respectively. Abbreviations have the same meanings as described in Table 2.

low invasion degree but weakened under moderate and high invasion degrees (Figs 1a-c). Correlations between $\mathrm{C}_{\mathrm{RA}}$ and height, leaf length, leaf width, total biomass, aboveground biomass, belowground biomass, vegetative biomass, and reproductive biomass of $C$. canadensis were strengthened under moderate and high invasion degrees, but were attenuated under low invasion degree 
(Figs 1a-c). Strong correlations between $\mathrm{C}_{\mathrm{RA}}$ and leaf width as well as leaf shape index of $C$. canadensis in Shenyang and Xiamen were observed (Figs 2a, d). Strong correlations between $\mathrm{C}_{\mathrm{RA}}$ and leaf shape index as well as reproductive branch number of $C$. canadensis in Jinan were observed (Fig. 2b). Strong correlations between $C_{R A}$ and height of $C$. canadensis in Zhenjiang were observed (Fig. 2c).

\section{Discussion}

Plants should maximize their living resources and achieve fitness advantage in multivariate environments in order to display a successful ecological strategy. For most plants, height plays an important role in their competitive ability $[25,26]$. Previous studies showed that plant height decreases with increasing latitude [25], but significantly increases with increasing temperature [27]. The present results indicated that the height of C. canadensis decreased with increasing latitude except Xiamen, which featured a subtropical marine climate. This finding is basically consistent with previous studies [25, 27]. Such an observation may be ascribed to the effects of temperature and latitude on plant height [27]. Meanwhile, the height of $C$. canadensis was positively correlated with its leaf length, leaf width, reproductive branch number, total biomass, aboveground biomass, belowground biomass, vegetative biomass, and reproductive biomass, as well as $\mathrm{C}_{\mathrm{RA}}$. Meanwhile, strong correlations between $\mathrm{C}_{\mathrm{RA}}$ and height of $C$. canadensis under moderate and high abundances and in Zhenjiang were also observed via PCA. The results suggested that plant height is a pivotal characteristic that governs the resource acquisition and competitive ability of plants $[25,26]-$ particularly in terms of competing for light, a major requirement for successful invasion of species [28].

As a key parameter for characterizing the growth competitiveness of plants [29], the total biomass of plants is improved when the population density is increased [30]. It was therefore expected that the biomass (including total biomass, aboveground biomass, belowground biomass, vegetative biomass, and reproductive biomass) of $C$. canadensis increase with increasing invasion degrees. However, the biomass of $C$. canadensis was not significantly affected by invasion degree. It is worth noting that the biomass of $C$. canadensis significantly increased with decreasing latitude gradient in Shenyang, Jianan, and Zhenjiang. Thus, latitude gradient rather than invasion degree was determined to be the most important environmental factor that exerts notable effects on the biomass of $C$. canadensis.

Invasive plants exert different abundances in the invaded ecosystems [1, 9-10], and the RA strategy of invasive plants may be significantly affected by their invasion process along different succession stages. Meanwhile, intraspecific competition among plants increases at high abundances and that invasive species must produce numerous subsequent generations.
Reproductive behaviors, which are important for connecting isolated populations and for colonizing new habitats via seed recruitment and dispersal, significantly contribute to the quick range expansion of plants [31]. Additionally, the high RA in a high abundance may benefit the expansion of plant population via seed recruitment and dispersal because the high reproductive efficiency of plants can be characterized as an adaptive strategy in competitive environments [32]. Contradicting the first hypothesis, however, the reproductive biomass and $\mathrm{C}_{\mathrm{RA}}$ of $C$. canadensis in this study were not significantly affected by invasion degree. This is inconsistent with previous results, which found that the reproductive allocation of plant species (Atriplex) maintain relative stability with increasing population density [33]. This phenomenon implied that the relatively high RA (allocate approximately $20 \%$ of total biomass into reproductive behaviors) of $C$. canadensis across different invasion degrees can achieve fitness advantage in broadening its habitat niches and can eventually attain a successful invasion. Previous studies also showed that high RA can enhance the invasiveness of invasive plants [34]. More importantly, the relatively high RA of $C$. canadensis did not significantly affect invasion degree.

One interesting discovery is that correlations $C_{R A}$ and belowground-aboveground biomass ratio of $C$. canadensis were strengthened under low invasion degree, whereas correlations between $\mathrm{C}_{\mathrm{RA}}$ and height, leaf length, leaf width, total, aboveground, belowground, vegetative, and reproductive biomass of $C$. canadensis were strengthened under moderate and high invasion degrees. Thus, the RA of $C$. canadensis may be principally influenced by the allocation between of belowground and aboveground biomasses at low invasion degree, but was affected by height, leaf size, and biomass at moderate and high invasion degrees. This indicated that intraspecific competition for resources may play an important role in the RA strategy of $C$. canadensis under high invasion degree because interspecies competition progressively decreased and intraspecific competition gradually increased with increasing invasion degree.

Previous studies showed that latitude can significantly affect plant functional traits via the difference in temperature and precipitation, mainly across the latitude gradient $[25,35]$. The result of the current study showed that the height, leaf length, leaf width, total biomass, aboveground biomass, belowground biomass, vegetative biomass, and reproductive biomass, as well as belowground-aboveground biomass ratio of $C$. canadensis increased with decreasing latitude gradient in Shenyang, Jianan, and Zhenjiang (except Xiamen). This may be due to the increasing mean annual temperature and precipitation with decreasing latitude gradient. Meanwhile, the $\mathrm{C}_{\mathrm{RA}}$ of $C$. canadensis in Jinan and Zhenjiang were significantly higher than those in Shenyang and Xiamen. The higher $\mathrm{C}_{\mathrm{RA}}$ of $C$. canadensis in warm temperate (Jinan) and subtropical monsoon climatic (Zhenjiang) zones may play an important role in the successful invasion of $C$. canadensis in the two climatic zones in China. The 
possible reason for this is that eastern China and northern China, in which $C$. canadensis vigorous occurs [11, 12], have the same or similar climate with their natural habitat in the original distribution region. Meanwhile, C. canadensis emerged when average daytime temperatures fluctuate between 10 and $15.5^{\circ} \mathrm{C}$ [13]. The mean annual temperature of Jinan and Zhenjiang were also in the range basically. This evidence presumably implies that $C$. canadensis can't bear higher temperature as well as lower temperature. One main reason is that $C$. canadensis originates from North America [11], which features a mild climate.

Plants with high biomass can invest a huge amount of biomass into their reproductive behaviors and exhibit a high $C_{R A}$ [15]. Previous research showed that the RA of plants significantly positively correlates with size $[6,15]$. The result of this study revealed that the $\mathrm{C}_{\mathrm{RA}}$ of C. canadensis was positively correlated with its total biomass, aboveground biomass, belowground biomass, and vegetative biomass. Meanwhile, strong correlations between $\mathrm{C}_{\mathrm{RA}}$ and aboveground biomass, belowground biomass, vegetative biomass, and reproductive biomass of C. canadensis under moderate and high invasion degrees were also observed based on the PCA results. As such, the second hypothesis was supported. The $\mathrm{C}_{\mathrm{RA}}$ of $C$. canadensis was also positively correlated with its height, leaf length, and leaf width, which are important factors that trigger the plants to expand and obtain more living space and resources (especially light) [35]. Temperature (including the mean annual air temperature, minimum temperature, maximum temperature, and annual accumulated temperature), instead of annual sunshine hours or annual precipitation, was determined to be the most important environmental factor that trigger pronounced effects on the RA strategy of C. canadensis. Similarly, other studies realized that temperature (particularly mean annual temperature) is more strongly correlated with plant traits than mean annual precipitation [36].

Variations in the morphological characteristics of C. canadensis under different invasion degrees along a latitude gradient may result from the differences in succession maturity and/or plant density in a small range. However, these characteristics are principally influenced by climatic factors (mainly temperature) in a large range. The results revealed that the invasion degree did not significantly affect all of the indices of $C$. canadensis, whereas the latitude gradient significantly affected all of the measured indices of C. canadensis, except for leaf shape index. This may be attributed to the fact that temperature is a key factor that determines the performance of plants [36] and therefore strongly affects their geographical distribution.

\section{Conclusions}

Overall, the successful ecological strategy of plants involves finding an optimal mode for the trade-off between the growth and reproductive behaviors to obtain maxi- mum fitness advantage in a changing environment. The changes in RA strategy of $C$. canadensis across different invasion degrees along a latitude gradient may play an important role in its successful invasion across many climatic zones.

\section{Acknowledgements}

We are grateful for the funding provided by the National Natural Science Foundation of China (31300343), and Open Science Research Fund of State Key Laboratory of State Key Laboratory of Soil and Sustainable Agriculture, China (Y20160023). We are very grateful to the anonymous reviewers for the insightful and constructive comments that greatly improved this manuscript.

\section{References}

1. SI C.C., LIU X.Y. WANG C.Y., WANG L., DAI Z.C., QI S.S., DU D.L. Different degrees of plant invasion significantly affect the richness of the soil fungal community. PLoS ONE 8, e85490, 2013.

2. WANG C.Y., XIAO H.G., ZHAO L.L., LIU J., WANG L., ZHANG F., SHI Y.C., DU D.L. The allelopathic effects of invasive plant Solidago canadensis on seed germination and growth of Lactuca sativa enhanced by different types of acid deposition. Ecotoxicology 25, 555, 2016.

3. CASTRO S., FERRERO V., COSTA J., SOUSA A.J., CASTRO M., NAVARRO L., LOUREIRO J. Reproductive strategy of the invasive Oxalis pescaprae: distribution patterns of floral morphs, ploidy levels and sexual reproduction. Biol. Invasions 5, 1863, 2013.

4. SUDING K.N., LAVOREL S., CHAPIN F.S., CORNELISSEN J.H.C., DÍAZ S., GARNIER E., GOLDBERG D., HOOPER D.U., JACKSON S.T., NAVAS M.-L. Scaling environmental change through the community-level: a trait-based response-and-effect framework for plants. Global Change Biol. 14, 1125, 2008.

5. CLELAND E.E. Trait divergence and the ecosystem impacts of invading species. New Phytol. 189, 649, 2011.

6. WEINER J., ROSENMEIER I., MASSONI E.S., VERA J.N., PLAZA E.H., SEBASTIA M.T. Is reproductive allocation in Senecio vulgaris plastic. Botany 87, 475, 2009.

7. NIU K.C., SCHMID B., CHOLER P., DU G.Z. Relationship between reproductive allocation and relative abundance among 32 species of a Tibetan alpine meadow: Effects of fertilization and grazing. PLoS ONE 7, e35448, 2012.

8. WANG X.Z., TAUB D.R., JABLONSKI L.M. Reproductive allocation in plants as affected by elevated carbon dioxide and other environmental changes: a synthesis using metaanalysis and graphical vector analysis. Oecologia 177, 1075, 2015.

9. WILSON S.D., PINNO B.D. Environmentally-contingent behaviour of invasive plants as drivers or passengers. Oikos 122, 129, 2013

10. WANG C.Y., ZHOU J.W., LIU J., WANG L., XIAO H.G. Reproductive allocation strategy of two herbaceous invasive plants across different cover classes. Pol. J. Environ. Stud. 26, 355, 2017.

11. HAO J.H., QIANG S., CHROBOCK T., VAN KLEUNEN 
M., LIU Q.Q. A test of Baker's Law: Breeding systems of invasive species of Asteraceae in China. Biol. Invasions 13, 571, 2011.

12. WEBER E., SUN S.Q., LI B. Invasive alien plants in China: diversity and ecological insights. Biol. Invasions 10, 1411, 2008.

13. MAIN C.L., STECKEL L.E., HAYES R.M., MUELLER T.C. Biotic and abiotic factors influence horseweed emergence. Weed Sci. 54, 1101, 2006.

14. BONSER S.P., AARSSEN L.W. Interpreting reproductive allometry: individual strategies of allocation explain sizedependent reproduction in plant populations. Perspect Plant Ecol. 11, 31, 2009.

15. HAUTIER Y., RANDIN C.F., STÖCKLIN J., GUISAN A. Changes in reproductive investment with altitude in an alpine plant. J. Plant Ecol. 2, 125, 2009.

16. MUNGER P., BLEIHOLDER H., HACK H., HEß M., STAUSS R., VAN DEN BOOM T., WEBER E. Phenological growth stages of the peanut plant (Arachis hypogaea L.): Codification and description according to the BBCH Scale. J. Agron. Crop Sci. 180, 101, 1998.

17. WANG Z., ZHANG L. Leaf shape alters the coefficients of leaf area estimation models for Saussurea stoliczkai in central Tibet. Photosynthetica 50, 337, 2012.

18. XIAO H.G., WANG C.Y., LIU J., WANG L., DU D.L. Insights into the differences in leaf functional traits of heterophyllous Syringa oblata under different light intensities. J. For. Res. 26, 613, 2015.

19. WANG C.Y., LIU J., XIAO H.G., DU D.L. Response of leaf functional traits of Cerasus yedoensis (Mats.) Yü li to serious insect attack. Pol. J. Environ. Stud. 25, 333, 2016.

20. WANG C.Y., XIAO H.G., LIU J., ZHOU J.W., DU D.L. Insights into the effects of simulated nitrogen deposition on leaf functional traits of Rhus typhina. Pol. J. Environ. Stud. 25, 1279, 2016.

21. SZYMURA M., SZYMURA T.H. Growth, phenology, and biomass allocation of alien Solidago species in Central Europe. Plant Species Biol. 30, 245, 2015.

22. SHANNON C.E., WEAVER W. The mathematical theory of communication. University of Illinois Press, Urbana, Illinois, $1,1949$.

23. SIMPSON E.H. Measurement of diversity. Nature 163, 688, 1949.

24. PIELOU E.C. The measurement of diversity in different types of biological collections. J. Theor. Biol. 13, 131, 1966

25. MOLES A.T., WARTON D.I., WARMAN L., SWENSON N.G., LAFFAN S.W., ZANNE A.E., PITMAN A., HEMMINGS F.A., LEISHMAN M.R. Global patterns in plant height. J. Ecol. 97, 923, 2009.

26. THOMSON F.J., MOLES A.T., AULD T.D., KINGSFORD R.T. Seed dispersal distance is more strongly correlated with plant height than with seed mass. J. Ecol. 99, 1299, 2011.

27. DE FRENNE P., GRAAE B.J., RODRÍGUEZ-SÁNCHEZ
F., KOLB A., CHABRERIE O., DECOCQ G., DE KORT H., DE SCHRIJVER A., DIEKMANN M., ERIKSSON O., GRUWEZ R., HERMY M., LENOIR J., PLUE J., COOMES D.A., VERHEYEN K. Latitudinal gradients as natural laboratories to infer species' responses to temperature. J. Ecol. 101, 784, 2013.

28. STANDISH R.J., ROBERTSON A.W., WILLIAMS P.A. The impact of an invasive weed Tradescantia fluminensis on native forest regeneration. J. Appl. Ecol. 38, 1253, 2001.

29. HWANG B.C., LAUENROTH W.K. Effect of nitrogen, water and neighbor density on the growth of Hesperis matronalis and two native perennials. Biol. Invasions 10, 771, 2008.

30. PING X.Y., JIA B.R., YUAN W.P., WANG F.Y., WANG Y.H., ZHOU L., XU Z.Z., ZHOU G.S. Biomass allocation of Leymus chinensis population: A dynamic simulation study. Chin. J. Appl. Ecol. 18, 2699, 2007. (In Chinese)

31. LIU H.Y., LIN Z.S., QI X.Z., ZHANG M.Y., YANG, H. The relative importance of sexual and asexual reproduction in the spread of Spartina alterniflora using a spatially explicit individual-based model. Ecol. Res. 29, 905, 2014.

32. BONSER S.P. High reproductive efficiency as an adaptive strategy in competitive environments. Funct. Ecol. 27, 876, 2013.

33. DRAKE D.R., UNGAR I.A. Effect of salinity, nitrogen and population density on the survival, growth, and reproduction of Atriplex Triangularis (Chenopodiaceae). Am. J. Bot. 76, $112,1989$.

34. VAN KLEUNEN M., WEBER E., FISCHER M. A metaanalysis of trait differences between invasive and non-invasive plant species. Ecol. Lett. 13, 235, 2010.

35. MENG F.Q., CAO R., YANG D.M., NIKLAS K.J., SUN S.C. Trade-offs between light interception and leaf water shedding: A comparison of shade- and sun-adapted species in a subtropical rainforest. Oecologia 174, 13, 2014.

36. MOLES A.T., PERKINS S.E., LAFFAN S.W., FLORESMORENO H., AWASTHY M., TINDALL M.L., SACK L., PITMAN A., KATTGE J., AARSSEN L.W., ANAND M., BAHN M., BLONDER B., CAVENDER-BARES J., CORNELISSEN J.H.C., CORNWELL W.K., DÍAZ S., DICKIE J.B., FRESCHET G.T., GRIFFITHS J.G., GUTIERREZ A.G., HEMMINGS F.A., HICKLER T., HITCHCOCK T.D., KEIGHERY M., KLEYER M., KUROKAWA H., LEISHMAN M.R., LIU K., NIINEMETS Ü., ONIPCHENKO V., ONODA Y., PENUELAS J., PILLAR V.D., REICH P.B., SHIODERA S., SIEFERT A., JR E.E.S., SOUDZILOVSKAIA N.A., SWAINE E.K., SWENSON N.G., VAN BODEGOM P.M., WARMAN L., WEIHER E., WRIGHT I.J., ZHANG H.X., ZOBEL M., BONSER S.P. Which is a better predictor of plant traits: temperature or precipitation? J. Veg. Sci. 25, 1167, 2014. 
